Research Article

\title{
Gentiopicroside Produces Endothelium-Independent Vasodilation by Deactivating the PI3K/Akt/Rho-Kinase Pathway in Isolated Rat Thoracic Aorta
}

\author{
Shangping Xing $\mathbb{D}^{1}$, Feifei Nong $\mathbb{D},{ }^{2}$ Jialiang Qin $\mathbb{D}^{1},{ }^{1}$ Huicai Huang $\mathbb{D}^{1},{ }^{1}$ Ruoting Zhan $\mathbb{D}$, \\ and Weiwen Chen iD ${ }^{1}$ \\ ${ }^{1}$ Research Center of Chinese Herbal Resource Science and Engineering, Key Laboratory of Chinese Medicinal Resource from Lingnan, \\ Ministry of Education, Guangzhou University of Chinese Medicine, Guangzhou 510006, China \\ ${ }^{2} \mathrm{Pi}$-Wei Institute, Science and Technology Innovation Center, Guangzhou University of Chinese Medicine, \\ Guangzhou 510006, China
}

Correspondence should be addressed to Weiwen Chen; weiwen_chen20@outlook.com

Received 21 January 2021; Accepted 3 May 2021; Published 15 May 2021

Academic Editor: Shusen Sun

Copyright (C) 2021 Shangping Xing et al. This is an open access article distributed under the Creative Commons Attribution License, which permits unrestricted use, distribution, and reproduction in any medium, provided the original work is properly cited.

\begin{abstract}
Gentiopicroside (GPS), a main active secoiridoid glucoside derived from the roots of perennial herbs in the Gentianaceae family, has antispasmodic and relaxant effects. However, the vasorelaxant effects of GPS on aortic rings and the molecular mechanisms involved in these effects are not yet clear. Therefore, we investigated whether GPS inhibits phenylephrine- (PE-) or KCl-induced contractions in isolated rat thoracic aortic rings. The present study found that GPS produced a dose-dependent relaxation in aortic rings precontracted with $\mathrm{PE}$ or $\mathrm{KCl}$ and significantly reduced $\mathrm{CaCl}_{2^{-}}$, narciclasine- (Rho-kinase activator-), and phorbol12,13-diacetate- (PKC activator-) induced vasocontractions. Pretreatment with NG-Nitroarginine methyl ester hydrochloride (L-NAME, NOS inhibitor), methylene blue (sGC inhibitor), indomethacin (COX inhibitor), 4-aminopyridine ( $\mathrm{K}_{\mathrm{V}}$ channel inhibitor), and glibenclamide ( $\mathrm{K}_{\mathrm{ATP}}$ channel inhibitor) had no influence on the vasorelaxant effect of $\mathrm{GPS}$, while $\mathrm{BaCl}_{2}\left(\mathrm{~K}_{\mathrm{ir}}\right.$ channel inhibitor), tetraethylammonium chloride $\left(\mathrm{K}_{\mathrm{Ca}}\right.$ channel inhibitor), ruthenium red (RYR inhibitor), and heparin $\left(\mathrm{IP}_{3} \mathrm{R}\right.$ inhibitor) significantly reduced GPS-induced vasorelaxation. Moreover, GPS pretreatment remarkably inhibited the influx of $\mathrm{Ca}^{2+}$ in vascular smooth muscle cells stimulated using $\mathrm{KCl}$ or PE-containing $\mathrm{CaCl}_{2}$ solution. Western blot analysis confirmed that GPS treatment inhibited PE-induced increases in the protein levels of p-Akt, p-myosin light chain (MLC), and p-myosinbinding subunit of myosin phosphatase 1 (MYPT1) in the aortic rings. Additionally, the vasorelaxation activity of GPS was attenuated upon pretreatment with LY294002 (PI3K/Akt inhibitor), Y27632 (Rho-kinase inhibitor), and verapamil (L-type Ca ${ }^{2+}$ channel inhibitor). These findings demonstrate that GPS exhibits endothelium-independent vasorelaxant effects through inhibition of voltage-dependent, receptor-operated, and inositol triphosphate receptor $\left(\mathrm{IP}_{3} \mathrm{R}\right) /$ ryanodine receptor- (RYR-) mediated $\mathrm{Ca}^{2+}$ channels as well as the PI3K/Akt/Rho-kinase signaling pathway.
\end{abstract}

\section{Introduction}

Hypertension, which is associated with vasoconstriction and vascular remodeling, is a serious threat to global public health by causing cardiovascular diseases, such as atherosclerosis, myocardial infarction, and vascular hypertrophy [1-4]. The incidence and mortality rates of hypertension are rapidly increasing worldwide; hypertension causes approximately 9 million deaths each year, and the total number of hyperten- sive patients in the world is expected to reach 1.5 billion by $2025[5,6]$. Therefore, lowering blood pressure and relaxing blood vessels can greatly alleviate the risk of cardiovascular disease development caused by elevated blood pressure.

Accumulating evidence [7-9] suggests that the hypercontractility of vascular smooth muscle (VSM) is closely related to raised blood pressure, while intracellular calcium concentration $\left(\left[\mathrm{Ca}^{2+}\right]_{\mathrm{in}}\right)$ is the primary regulator of tension in VSM. $\mathrm{Ca}^{2+}$ is a critical factor in excitation-contraction coupling in 
VSM, an increase in $\left[\mathrm{Ca}^{2+}\right]_{\text {in }}$ results in vasoconstriction and a decrease in $\left[\mathrm{Ca}^{2+}\right]_{\text {in }}$ results in vasodilation [10]. It is well known that the regulation of vascular tone is mainly triggered by releasing vasodilator factors [nitric oxide (NO), prostacyclin $\left.\left(\mathrm{PGI}_{2}\right)\right]$, changing the resting membrane potential $\left(\mathrm{K}^{+}\right.$channels), the influx of extracellular $\mathrm{Ca}^{2+}$ through receptor-operated calcium channel (ROCC) and voltagedependent calcium channel (VDCC, including L-type $\mathrm{Ca}^{2+}$ channels), and the release of intracellular $\mathrm{Ca}^{2+}$ from sarcoplasmic reticulum $[11,12]$. Additionally, many signaling pathways have been reported to play an essential role in vasoconstriction processes [13]. For example, PI3K/Akt upon activation can induce the VSM constriction by coupling membrane receptors to L-type $\mathrm{Ca}^{2+}$ channels $[14,15]$. PKC and Rho-kinase $\mathrm{Ca}^{2+}$-sensitizing pathways leading to myosin phosphatase inhibition are critically involved in $\alpha 1$-adrenoceptor-mediated VSM contraction [16]. Although many vasodilators are commercially available such as nitroglycerin (NO donor drug), verapamil ( $\mathrm{Ca}^{2+}$ channel antagonist), and fasudil (ROCK inhibitor), they are limited by their adverse effects and patient compliance $[17,18]$. Therefore, the development of natural vasodilator compounds has far-reaching research significance and high relevance for the discovery of new treatment of cardiovascular diseases.

Gentiopicroside (GPS, $\mathrm{C}_{16} \mathrm{H}_{20} \mathrm{O}_{9}$, Figure 1(a)) is a secoiridoid glucoside that is isolated from the roots of perennial herbs in the Gentianaceae family, such as Gentiana straminea Maxim., Gentiana macrophylla Pall., Gentiana manshurica Kitag., Gentiana dahurica Fisch., and Gentiana scabra Bge., which are used widely as medicinal herbs in China for the treatment of rheumatoid arthritis, hemiplegia, arthralgia, stroke, and hypertension [19]. GPS has been proven to display potential protective effects against osteoarthritis, hepatitis, diabetic renal fibrosis, osteoclastogenesis, and alcoholic hepatosteatosis [20]. Kesavan et al. [21] reported that Gentiana lutea root extracts consisting of GPS significantly inhibit the proliferation of VSMCs induced by platelet-derived growth factor- $\mathrm{BB}$, which may have a cardiovascular protective effect in the prevention and treatment of atherosclerosis. Given that GPS can inhibit the spontaneous contractions of smooth muscle induced by histamine, $\mathrm{KCl}$, and $\mathrm{BaCl}_{2}$ in isolated pig ileum [22], we hypothesized that GPS may inhibit vascular contraction by blocking ion channels or the corresponding signal transduction pathways.

To the best of our knowledge, the effects of GPS on aortic rings and the molecular mechanisms involved in these effects have not yet been clarified. Therefore, this study aims to investigate the effects of GPS on the vasoconstriction of aortic rings induced by $\mathrm{PE}$ and $\mathrm{KCl}$. We also explored the underlying mechanisms of the GPS-promoted vasodilatation effects by studying $\mathrm{Ca}^{2+}$ and $\mathrm{K}^{+}$channels and the PI3K/Akt/Rhokinase signaling pathway. These data could provide a novel insight into the molecular mechanisms underlying the vasodilatory effects of GPS.

\section{Materials and Methods}

2.1. Preparation of Rat Thoracic Aortic Rings. Fifty-one specific pathogen-free grade healthy male Sprague-Dawley rats
(4-6 months old and weighing an average $250 \mathrm{~g}$ ) were obtained from the Experimental Animal Center of Guangzhou University of Chinese Medicine (no: SCXK-20130020). All procedures in this study were approved by the Ethics Committee for the Use of Experimental Animals of Guangzhou University of Chinese Medicine (Permit no: 20190513056). As described previously [23], after the SD rats were euthanized, the thoracic aorta was carefully dissected and placed into ice-cold modified Krebs solution. The isolated aortas were cleaned of adipose and connective tissue and cut into 3-4 $\mathrm{mm}$ long rings, which were then mounted with two stainless steel hooks into an organ bath containing Krebs solution (gassed with $95 \% \mathrm{O}_{2}$ and $5 \% \mathrm{CO}_{2}$ at $37^{\circ} \mathrm{C}$ ) at an initial force of $1 \mathrm{~g}$ tension. The alternation of isometric tension was recorded with a force-displacement transducer connected to a ML870 Power Lab Biological Signal Collection System (AD Instruments, Castle Hill, NSW, Australia). The endothelium of the aortic ring was removed carefully by rotating a manipulator inside the ring lumen, and its absence was verified by examining the capacity of $10 \mu \mathrm{M}$ acetylcholine to induce less than $10 \%$ relaxation of rings precontracted with $1 \mu \mathrm{M}$ PE. The endothelium was considered intact when the relaxation was more than $80 \%$ in response to acetylcholine. Only the aortic rings that met this standard were used for the subsequent experiments.

2.2. Action of GPS on Baseline Tension. After the aortic rings, with or without endothelium, were stabilized at primary $1 \mathrm{~g}$ tension, cumulative concentrations of GPS $(0,5,10,20,40$, 80,160 , and $320 \mu M$ ) were added to the organ chambers. Changes in vascular tension were recorded, and a cumulative concentration-response curve for GPS was obtained.

2.3. Effect of GPS on Aortic Rings Precontracted with PE and $\mathrm{KCl}$. After equilibration for $60 \mathrm{~min}, \mathrm{PE}(1 \mu \mathrm{M})$ or $\mathrm{KCl}$ $(60 \mathrm{mM})$ was used to induce a steady contraction in the aortic ring with or without endothelium. This was followed by the addition of cumulative concentrations of GPS $(0,5,10,20$, $40,80,160$, and $320 \mu M$ ) to the ring for $20 \mathrm{~min}$ to verify its vasorelaxant activity. The vasodilation rate (\%) was calculated as follows: Relaxation $(\%)=($ maximal tension by PE or $\mathrm{KCl}$ - tension after incubation with corresponding compounds)/(maximal tension by $\mathrm{PE}$ or $\mathrm{KCl}$ - basal tension before precontraction with $\mathrm{PE}$ or $\mathrm{KCl}) \times 100 \%$.

2.4. Effects of Various Inhibitors on GPS-Induced Vasodilation. To elucidate the role of the endothelium, $\mathrm{K}^{+}$ channel, and PI3K/Akt/Rho-kinase pathways in GPSmediated vasodilation, the aortic rings with intact endothelium were preincubated with nitric oxide synthase (NOS) inhibitor (100 $\mu \mathrm{M}$ L-NAME), cyclooxygenase (COX) inhibitor $(100 \mu \mathrm{M}$ indomethacin), and soluble guanylyl cyclase (sGC) inhibitor (100 $\mu \mathrm{M}$ methylene blue), respectively, for $30 \mathrm{~min}$, while the aortic rings without endothelium were preincubated with different $\mathrm{K}^{+}$channel blockers of tetraethylammonium chloride (TEA, $10 \mathrm{mM}$ ), 4-aminopyridine (4AP, $1 \mathrm{mM}), \mathrm{BaCl}_{2}$ (1 mM), glibenclamide (0.01 mM), L-type $\mathrm{Ca}^{2+}$ channel inhibitor $(100 \mu \mathrm{M}$ verapamil), PI3K/Akt inhibitor $(10 \mu \mathrm{M}$ LY294002), and Rho-kinase inhibitor $(10 \mu \mathrm{M}$ 
<smiles>C=CC1C2=CCOC(=O)C2=COC1O[C@H]1O[C@H](CO)C(O)[C@H](O)C1O</smiles>

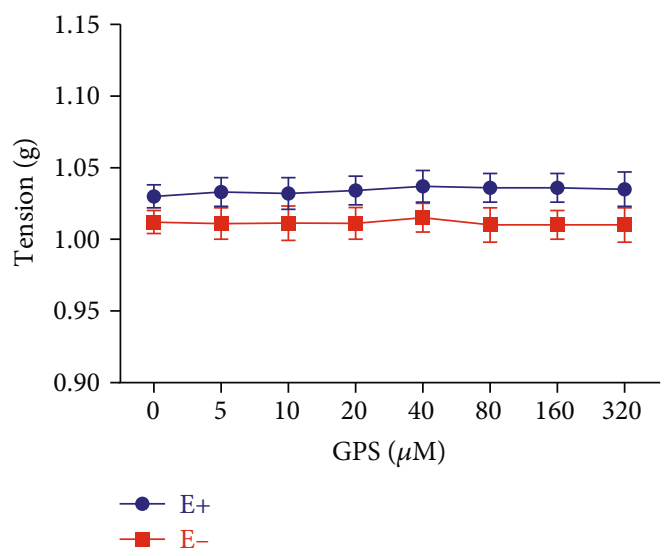

(a)

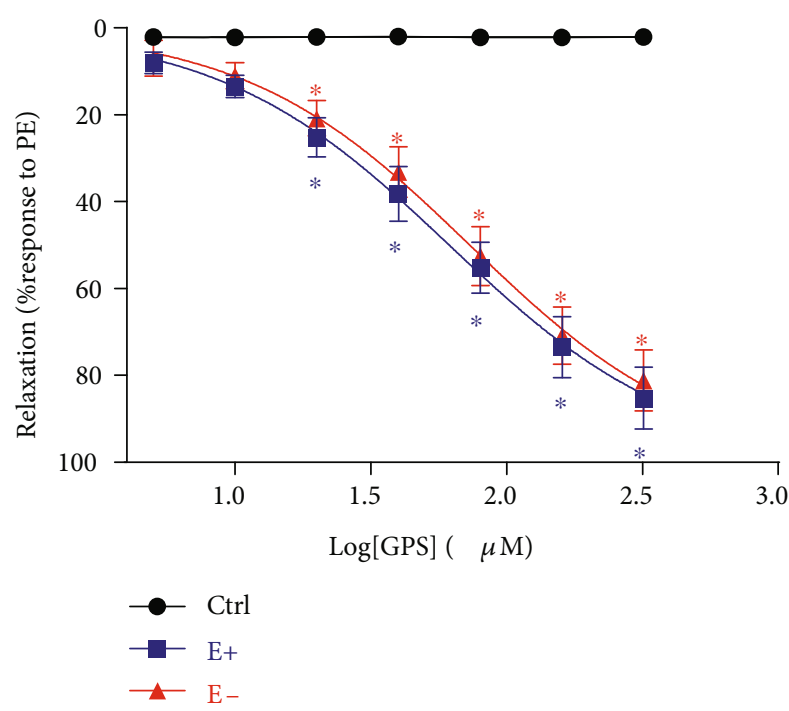

(c) (b)

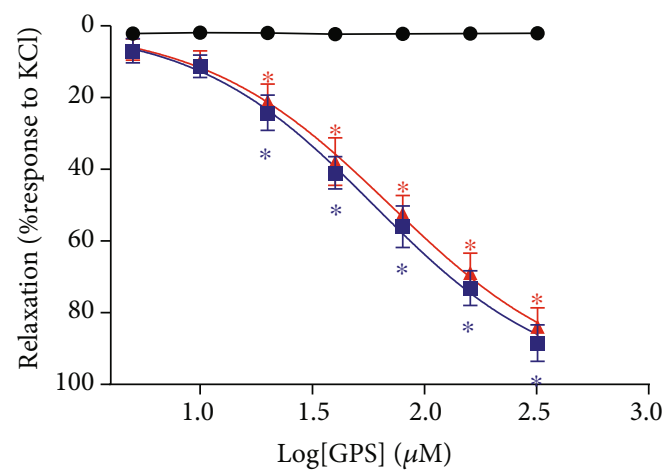

(d)

FIGURE 1: Effects of GPS on the vasorelaxation of thoracic aortic rings. (a) Chemical structure of GPS. (b) Direct effects of GPS (5, 10, 20, 40, $80,160$, and $320 \mu M)$ on the thoracic aorta tension. (c) Cumulative concentration-response curves of GPS $(5,10,20,40,80,160$, and $320 \mu M)$ on endothelium-intact (E+) and endothelium-denuded (E-) aortic rings precontracted with $1 \mu \mathrm{M} \mathrm{PE}$ or (d) $60 \mathrm{mM} \mathrm{KCl}$. Data are presented as mean \pm SEM $(n=6) .{ }^{*} p<0.05$ compared to the control group.

Y27632) for $30 \mathrm{~min}$ (all inhibitors were obtained from MedChem Express, NJ, USA). After achieving a plateau of PEinduced contracted tension, GPS was added in a cumulative manner $(20,80$, and $160 \mu M)$ for $20 \mathrm{~min}$, and the concentration-response curves were recorded.

\subsection{Effect of GPS on Extracellular $\mathrm{Ca}^{2+}$-Induced Contraction.} After the aortic rings without endothelium were incubated with $\mathrm{Ca}^{2+}$-free Krebs solution [containing 0.5 mM Ethylenebis (oxyethylenenitrilo) tetraacetic acid (EGTA) and $60 \mathrm{mM}$ $\mathrm{KCl}$ ] for $30 \mathrm{~min}$, the rings were treated with GPS $(20,80$, and $160 \mu M)$ for $20 \mathrm{~min}$, and subsequently, $\mathrm{CaCl}_{2}(0.1,0.3$, 1,3 , and $10 \mathrm{mM}$ ) was added cumulatively to obtain concentration-response curves.

2.6. Cell Culture. The rat thoracic aorta vascular smooth muscle A7r5 cell line was purchased from Shanghai Cell Bank (Shanghai, China). The cells were cultured in high-glucose
Dulbecco's Modified Eagle Medium (DMEM) supplemented with $10 \%$ fetal bovine serum and $1 \%$ penicillin-streptomycin solution (all these reagents were obtained from Gibco, Grand Island, NY, USA) and incubated at $37^{\circ} \mathrm{C}$ with $5 \% \mathrm{CO}_{2}$.

2.7. Effect of GPS on $\left[\mathrm{Ca}^{2+}\right]_{\text {in }}$ in A7r5 Cells. A7r 5 cells $\left(5 \times 10^{4}\right.$ cells/well) in chamber slides were loaded with $10 \mu M$ Fluo4/AM (Thermo Fisher Scientific, Grand Island, NY, USA) in $\mathrm{Ca}^{2+}$-free Krebs solution for $30 \mathrm{~min}$ at $37^{\circ} \mathrm{C}$ with $5 \% \mathrm{CO}_{2}$ in the dark, as described previously [24]. A7r5 cells were then washed thrice with $\mathrm{Ca}^{2+}$-free Krebs solution and incubated with $\mathrm{Ca}^{2+}$-free Krebs solution for $20 \mathrm{~min}$ to generate free Fluo-4. After treatment with GPS $(20,80$, and $160 \mu M)$ for $30 \mathrm{~min}$ at $37^{\circ} \mathrm{C}$ with $5 \% \mathrm{CO}_{2}$ in the dark, $100 \mathrm{mM} \mathrm{KCl}$ in Krebs solution, or $1 \mu \mathrm{M}$ PE-2.5 $\mathrm{mM} \mathrm{CaCl}_{2}$ in $\mathrm{Ca}^{2+}$-free Krebs solution was added to induce fluorescence emission during detection. Fluorescence was captured using laser confocal microscopy (Zeiss 880, Jena, Germany). 
2.8. Effect of GPS on Intracellular $\mathrm{Ca}^{2+}$. Aortic rings without endothelium were firstly contracted with $60 \mathrm{mM} \mathrm{KCl}$ in normal Krebs solution to assure rich $\mathrm{Ca}^{2+}$ storage in the sarcoplasmic reticulum. Following this, the rings were allowed to rest in $\mathrm{Ca}^{2+}$-free Krebs solution (containing 0.5 mM EGTA) for $30 \mathrm{~min}$. (1) On one hand, the rings were incubated with $10 \mu \mathrm{M}$ narciclasine (Rho-kinase activator) or $10 \mu \mathrm{M}$ phorbol-12,13-diacetate (PKC activator) and then treated with GPS $(20,80$, and $160 \mu M)$ for $20 \mathrm{~min}$. (2) On the other hand, the rings were incubated with $50 \mathrm{mg} / \mathrm{L}$ heparin [inositol triphosphate receptor $\left(\mathrm{IP}_{3} \mathrm{R}\right)$ inhibitor] or $10 \mu \mathrm{M}$ ruthenium red [ryanodine receptor (RYR) inhibitor] for $30 \mathrm{~min}$ (all activators and inhibitors were obtained from MedChem Express), and then, the rings precontracted with PE $(1 \mu \mathrm{M})$ were treated with GPS $(20,80$, and $160 \mu \mathrm{M})$ for $20 \mathrm{~min}$, followed by recording of the concentration-response curves.

2.9. Western Blot Analysis. Isolated aortic rings without endothelium were transferred to DMEM and incubated at $37^{\circ} \mathrm{C}$ with $5 \% \mathrm{CO}_{2}$. PE was added to the medium for $30 \mathrm{~min}$, followed by GPS $(160 \mu \mathrm{M})$ for $20 \mathrm{~min}$. Aortic rings were snap frozen with liquid nitrogen; then, the protein was extracted using radioimmunoprecipitation assay (RIPA) lysis buffer mixed with $1 \%$ phenylmethanesulfonyl fluoride (PMSF). According to the standard WB procedure, the membranes were incubated with primary antibodies against GAPDH, Akt, p-Akt, MLC, p-MLC, MYPT1, and pMYPT1 (1:1000 dilution, Cell Signaling Technologies, Beverly, MA, USA) overnight at $4^{\circ} \mathrm{C}$, followed by incubation with the corresponding secondary antibody for $1 \mathrm{~h}$. The protein bands were visualized using an ECL reagent (EMD Millipore) and analyzed using the Tanon 5200 image acquisition system (Tanon Science and Technology Co., Ltd., Shanghai, China).

2.10. Statistical Analysis. All data are expressed as mean \pm SEM. Data were plotted using the GraphPad Prism software (version 6.0; GraphPad Software, Inc.), with sigmoidal curve fitting performed by nonlinear regression using the Prism software. The maximal relaxation or contraction response was presented as $E_{\max }$, and the half-maximal effective concentration was presented as $\mathrm{EC}_{50}$. Data were analyzed by one-way and two-way analysis of variance (ANOVA), followed by Bonferroni's as a posttest, using the SPSS software (version 23.0; IBM Corp.). Differences with $p<0.05$ were considered statistically significant.

\section{Results}

3.1. Effects of GPS on PE- or KCl-Induced Contractions in Aortic Rings. As shown in Figure 1(b), there was no change in the tension of rat thoracic aortic rings with or without endothelium after direct application of cumulative concentrations of GPS $(5-320 \mu M)$. The results indicated that GPS has no direct vasoconstriction and vasorelaxation effects on aortic rings that sustained resting tension. However, GPS (5-320 $\mu M)$ produced a dose-dependent relaxation in the aortic rings with or without endothelium that were precontracted with PE or $\mathrm{KCl}$ (Figures 1(c) and 1(d)). The halfmaximal effective concentration $\left(\mathrm{EC}_{50}\right)$ values of the relaxant effects of GPS for endothelium-intact and endotheliumdenuded aortic rings were $76.56 \pm 3.62$ and $78.81 \pm 3.06$ $\mu M$, respectively, in case of PE-induced contraction, and $72.68 \pm 4.18$ and $75.19 \pm 4.22 \mu \mathrm{M}$, respectively, in case of $\mathrm{KCl}$-induced contraction. No significant difference was observed in GPS relaxing PE- or KCl-induced contractions between endothelium-intact and endothelium-denuded aortic rings $\left(E_{\max } / \mathrm{PE}\right.$ : E+, $85.29 \pm 3.55 \%$ vs. E-, $81.32 \pm 3.46 \%$, $p>0.05 ; E_{\max } / \mathrm{KCl}: \mathrm{E}+, 88.52 \pm 2.88 \%$ vs. E-, $83.89 \pm 2.69 \%$, $p>0.05)$. These results showed that the vasodilation of GPS on aortic rings precontracted with $\mathrm{PE}$ or $\mathrm{KCl}$ was endothelium-independent.

3.2. Effects of Endothelial Dilated Mediators on GPS-Induced Vasorelaxation. It has been reported [25] that NOS, sGC, and $\mathrm{COX}$ are essential in the formation and activation of $\mathrm{NO}$ and $\mathrm{PGI}_{2}$, which are the main endothelium-dependent relaxing factors. Pretreatment with L-NAME (NOS inhibitor), indomethacin (COX inhibitor), and methylene blue (sGC inhibitor) had no interfering effect on GPS- $(20,80$, and $160 \mu \mathrm{M})$ induced vasorelaxation $\left(E_{\max }: 72.76 \pm 2.66 \%, 73.80 \pm 2.71 \%\right.$ , $75.28 \pm 3.19 \%)$ in aortic rings precontracted with $\mathrm{PE}$ when compared to control group ( $\left.E_{\max }: 78.58 \pm 2.13 \%\right)(p>0.05)$, which further confirmed that GPS-induced vasorelaxation was endothelium-independent (Figure 2).

3.3. Effects of $\mathrm{K}^{+}$Channels on GPS-Induced Vasorelaxation. As shown in Figure 3, pretreatment with Gli [ATP-sensitive $\mathrm{K}^{+}\left(\mathrm{K}_{\mathrm{ATP}}\right)$ channel inhibitor] and 4-AP [voltage-dependent $\mathrm{K}^{+}\left(\mathrm{K}_{\mathrm{V}}\right)$ channel inhibitor] had no effect on GPS- $(20,80$, and $160 \mu \mathrm{M})$ induced vasorelaxation $\left(E_{\max }: 73.98 \pm 3.17 \%\right.$, $70.29 \pm 2.92 \%)$ in aortic rings without endothelium that were precontracted with $\mathrm{PE}$, compared to the control group ( $E_{\max }$ : $77.56 \pm 3.03 \%)(p>0.05)$. In contrast, pretreatment with TEA $\left[\mathrm{Ca}^{2+}\right.$-activated $\mathrm{K}^{+}\left(\mathrm{K}_{\mathrm{Ca}}\right)$ channel inhibitor] or $\mathrm{BaCl}_{2}$ [inward rectifier $\mathrm{K}^{+}\left(\mathrm{K}_{\mathrm{ir}}\right)$ channel inhibitor] significantly reduced the vasorelaxation by GPS with $E_{\max }$ of $25.68 \pm$ $3.71 \%$ or $20.58 \pm 3.35 \%$, compared to the control group $(p<0.05)$. These results indicated that the activation of $\mathrm{K}^{+}$ channels may be related to the vasodilation of GPS.

3.4. GPS Inhibited Extracellular $\mathrm{Ca}^{2+}$ Influx in Aortic Rings and $A 7 r 5$ Cells. In the high $\mathrm{K}^{+}$and $\mathrm{Ca}^{2+}$-free Krebs solutions, the cumulative addition of $\mathrm{CaCl}_{2}(0.1,0.3,1,3$, and $10 \mathrm{mM})$ induced concentration-dependent contractions in the aortic rings without endothelium, while GPS $(20,80$, and $160 \mu \mathrm{M})$ treatment significantly inhibited these $\mathrm{CaCl}_{2}$-induced contractions $\left(E_{\max }: 68.65 \pm 3.89 \%, 56.92 \pm 3.52 \%, 38.52 \pm 2.23\right.$ $\%$, vs. $100 \pm 0.01 \%$ in control group, $p<0.05$ ) (Figure 4 ). To further investigate the effect of GPS on extracellular $\mathrm{Ca}^{2+}$ influx, we used a Fluo-4/AM molecular probe to observe intracellular $\mathrm{Ca}^{2+}$ fluorescence intensity in rat VSM A7 $\mathrm{r} 5$ cells. The results revealed that pretreatment with GPS $(20,80$, and $160 \mu \mathrm{M})$ concentration dependently and significantly reduced the fluorescence intensity of $\mathrm{A} 7 \mathrm{r} 5$ cells stimulated with $\mathrm{CaCl}_{2}$ or $\mathrm{KCl}$ (Figure 5). These results confirmed that the inhibition of extracellular $\mathrm{Ca}^{2+}$ influx might be involved in the underlying mechanism of GPS in the promotion of vasorelaxation. 


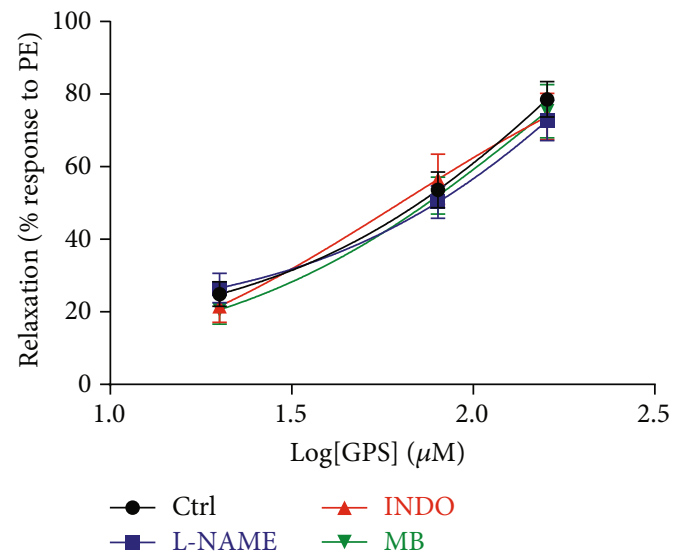

Figure 2: Effects of dilated mediators, including L-NAME, indomethacin (INDO), and methylene blue (MB) on GPS- $(20,80$, and $160 \mu \mathrm{M})$ induced vasorelaxation in endothelium-intact aortic rings precontracted with $\mathrm{PE}$. Data are presented as mean $\pm \mathrm{SEM}$ $(n=6) .{ }^{*} p<0.05$ compared to the control group.

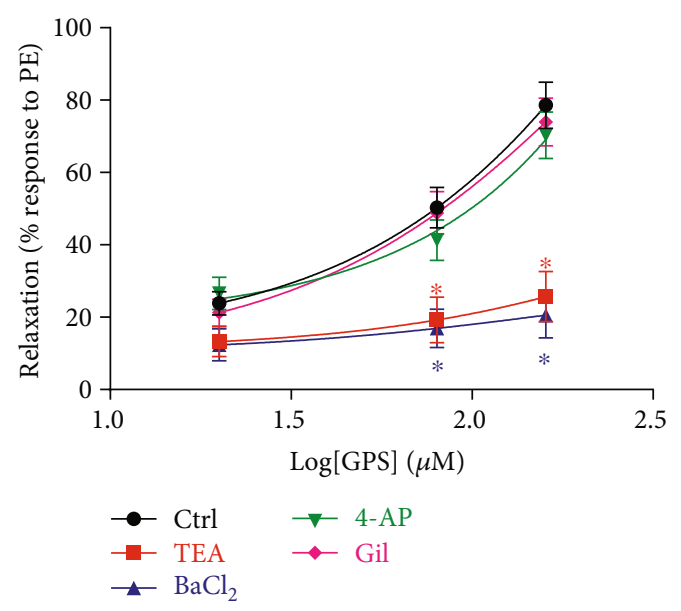

FIgURE 3: Effects of $\mathrm{K}^{+}$channel blockers, including tetraethylammonium chloride (TEA), $\mathrm{BaCl}_{2}, 4$-aminopyridine (4AP), and glibenclamide (Gli) on GPS- $(20,80$, and $160 \mu \mathrm{M})$ induced vasorelaxation in endothelium-denuded aortic rings precontracted with PE. Data are presented as mean \pm SEM $(n=6)$. ${ }^{*} p<0.05$ compared to the control group.

3.5. GPS Inhibited Intracellular $\mathrm{Ca}^{2+}$ Release in Aortic Rings. Preincubation with GPS $(20,80$, and $160 \mu \mathrm{M})$ significantly decreased PE-, narciclasine- (Rho-kinase activator) or phorbol-12,13-diacetate- (PKC activator) induced contractions of aortic rings in $\mathrm{Ca}^{2+}$-free solution, compared to the control group $(p<0.05$, Figures $6(\mathrm{a})-6(\mathrm{c}))$. The results indicated that GPS could inhibit the vasoconstriction caused by the release of intracellular $\mathrm{Ca}^{2+}$. Furthermore, pretreatment with ruthenium red (RYR antagonist) or heparin ( $\mathrm{IP}_{3} \mathrm{R}$ antagonist) significantly reduced the vasodilatory effects of GPS on aortic rings precontracted with $\mathrm{PE}$ in $\mathrm{Ca}^{2+}$-free solution $\left(E_{\max }\right.$ : $32.66 \pm 2.91 \%$ in ruthenium red, $48.25 \pm 3.22 \%$ in heparin vs. $80.58 \pm 3.37 \%$ in control group, $p<0.05$ in both, respectively) (Figure 6(d)). These results suggested that the mecha-

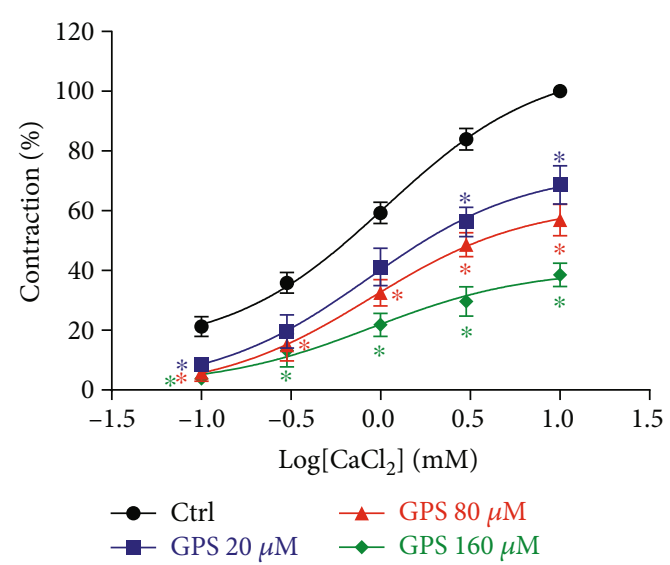

FIgURE 4: Effects of GPS $(20,80$, and $160 \mu \mathrm{M})$ on $\mathrm{CaCl}_{2^{-}}(0.1,0.3,1$, 3 , and $10 \mathrm{mM}$ ) induced contractions of endothelium-denuded aortic rings in high $\mathrm{K}^{+}$and $\mathrm{Ca}^{2+}$-free Krebs solution. Data are presented as mean $\pm \operatorname{SEM}(n=6) .{ }^{*} p<0.05$ compared to the control group.

nisms by which GPS inhibits vasoconstriction seem to be associated with the blockade of $\mathrm{IP}_{3} \mathrm{R} / \mathrm{RYR}$-mediated intracellular $\mathrm{Ca}^{2+}$ channels in the sarcoplasmic reticulum and the Rho-kinase-PKC induced MLC phosphorylation.

3.6. GPS Suppressed the Activation of the PI3K/Akt/RhoKinase Signaling Pathway. Increasing evidence suggests that the PI3K/Akt/Rho-kinase signaling pathway plays a crucial role in vasoconstriction by stimulating the L-type $\mathrm{Ca}^{2+}$ channel [26]. Western blotting analyses showed that GPS significantly inhibited the upregulation of p-Akt, p-MYPT1, and pMLC protein levels induced by $\mathrm{PE}$ in aortic rings without endothelium compared to the PE group $(p<0.05)$, while the levels of total Akt, MYPT1, and MLC were unchanged (Figure $7(\mathrm{a})$ ). In addition, we found that pretreatment with verapamil (L-type $\mathrm{Ca}^{2+}$ channel blocker), LY294002 (PI3K/Akt inhibitor), and Y27632 (Rho-kinase inhibitor) significantly attenuated the vasodilation by GPS with $E_{\max }$ of $28.68 \pm 3.43 \%, 31.52 \pm 2.83 \%$, and $39.57 \pm 3.39 \%$ in aortic rings precontracted with $\mathrm{PE}$, compared to the control group with $E_{\max }$ of $81.39 \pm 3.61 \%(p<0.05$, Figure $7(\mathrm{~b}))$. Thus, these findings confirmed that the vasorelaxation activity of GPS probably involves the PI3K/Akt/Rho-kinase signaling pathway.

\section{Discussion}

Hypertension, angina pectoris, and acute coronary syndrome are usually accompanied by the pathological characters of decreased vasodilation ability and enhanced vasoconstriction that may lead to vessel occlusion and insufficient blood supply to important organs and tissues, which serve as the main major risk factors for cardiovascular diseases [27]. Therefore, improving the vasodilation function of patients is considered an effective method for the prevention and treatment of cardiovascular diseases [28]. To date, rat thoracic aortic rings are used by many researchers as classical models to investigate the vasorelaxation effects of drugs. The present study is the first to investigate the vasodilatory effect of GPS in 

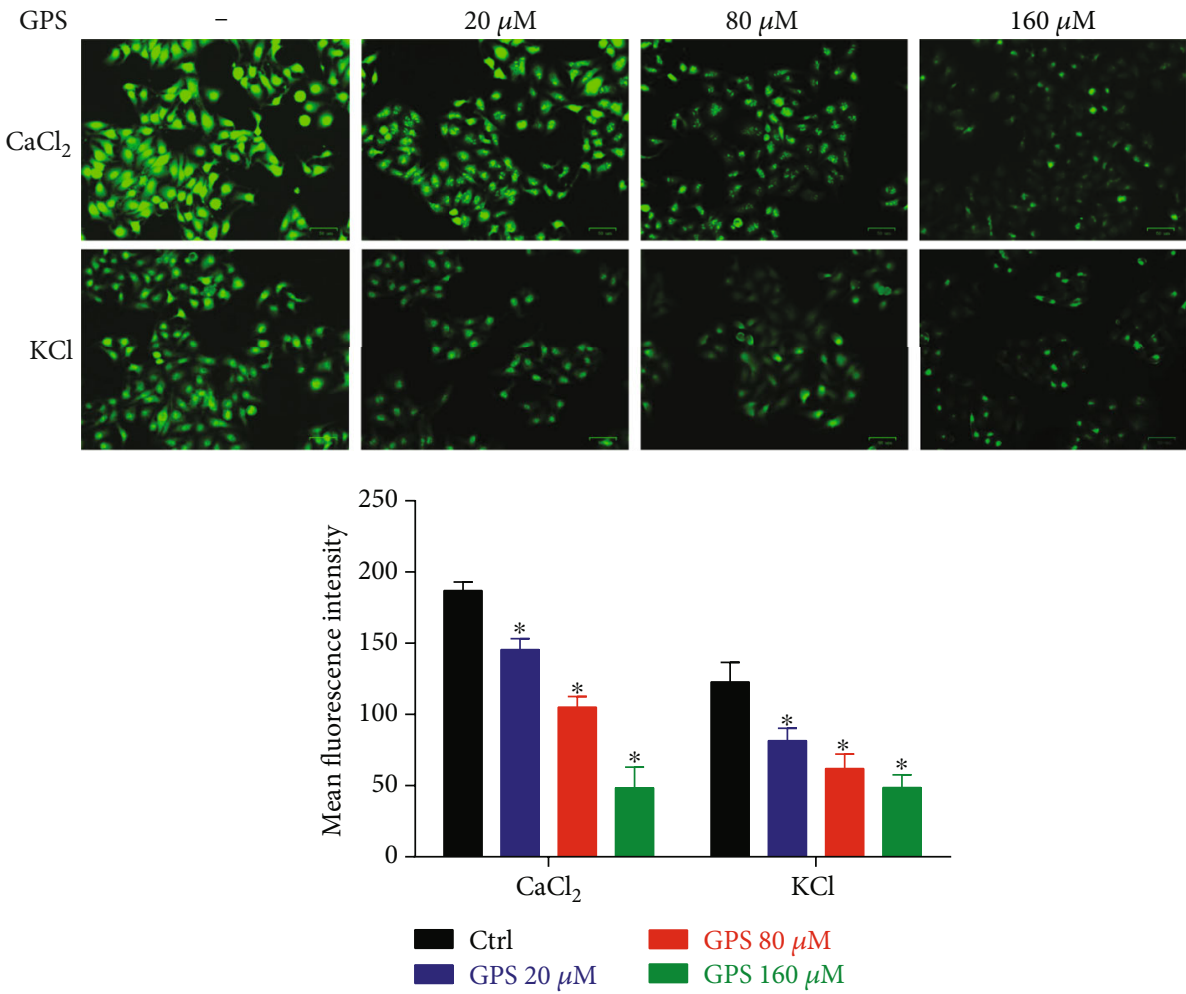

FIGURE 5: Effects of GPS $(20,80$, and $160 \mu \mathrm{M})$ on the fluorescence intensity of vascular smooth muscle A7r5 cells stimulated using $1 \mu \mathrm{M}$ PE$2.5 \mathrm{mM} \mathrm{CaCl}_{2}$ in $\mathrm{Ca}^{2+}$-free Krebs solution or $100 \mathrm{mM} \mathrm{KCl}$ in Krebs solution. Images were taken using laser confocal microscopy. Scale bar: $50 \mu \mathrm{m}$. Green fluorescence intensities represent the intracellular calcium concentration $\left(\left[\mathrm{Ca}^{2+}\right]_{\mathrm{in}}\right)$ levels. Data are presented as mean $\pm \mathrm{SEM}$ $(n=6) .{ }^{*} p<0.05$ compared to the control group.

isolated rat thoracic aorta and to investigate the mechanism of action involved.

Vasodilation can be divided into two types: endotheliumdependent and endothelium-independent. The former is mainly related to the production of endothelium-derived relaxing factor NO and prostaglandins in the thoracic aorta, while the latter is related to a reduction in $\left[\mathrm{Ca}^{2+}\right]_{\text {in }}$ levels caused by drugs directly acting on VSM [29]. Contraction of VSM depends on the influx of extracellular $\mathrm{Ca}^{2+}$ through VDCC and ROCC in the cell membrane and the release of intracellular $\mathrm{Ca}^{2+}$ through stimulation of $\mathrm{IP}_{3} \mathrm{R}$ - and RYRmediated $\mathrm{Ca}^{2+}$ channels in the sarcoplasmic reticulum [30]. $\mathrm{KCl}$-induced contractions mainly result from membrane depolarization and openness of VDCC, while PE, an $\alpha$-adrenoreceptor agonist, leads to an aortic contraction in response to extracellular $\mathrm{Ca}^{2+}$ influx through ROCC [31]. Previous studies $[32,33]$ have demonstrated that $4.2 \mathrm{mM}$ of gentiopicroside exhibited no significant cytotoxicity to chondrocytes, and the methanol extract of Swertia corymbosa (family: Gentianaceae) did not produce any mortality and delayed toxicity orally up to $2000 \mathrm{mg} / \mathrm{kg}$ (approximately $81.45 \mathrm{mg} / \mathrm{kg}$ of GPS) when the animals were monitored for a further 14 days. The data in the present study indicates that GPS dosedependently produced vasorelaxation effects on aortic rings with endothelium that were precontracted with $\mathrm{PE}$ or $\mathrm{KCl}$; this effect of GPS was not significantly different in aortic rings without endothelium. Furthermore, we found that the GPS-induced vasorelaxation effect was unaffected upon pre- treatment with NOS inhibitor (L-NAME), COX inhibitor (indomethacin), and sGC inhibitor (methylene blue) in aortic rings with endothelium. These results evidently indicated that the vasodilation effects of GPS on thoracic aortic rings were endothelium-independent, independent of endothelium-derived relaxing factors such as $\mathrm{NO}$ and $\mathrm{PGI}_{2}$, and that GPS is likely to directly act on the VSM by inhibition of VDCC and ROCC.

$\mathrm{K}^{+}$channels play a critical role in regulating vascular tone by $\mathrm{K}^{+}$efflux, causing cell membrane hyperpolarization, and inhibiting extracellular $\mathrm{Ca}^{2+}$ influx leading to vasodilation [34]. The four types of $\mathrm{K}^{+}$channels including $\mathrm{K}_{\mathrm{ATP}}, \mathrm{K}_{\mathrm{ir}}$, $\mathrm{K}_{\mathrm{Ca}}$, and $\mathrm{K}_{\mathrm{V}}$ on the VSM can be blocked using Gli, $\mathrm{BaCl}_{2}$, TEA, and 4-AP, respectively. These results showed that the effects of GPS in PE-precontracted rings were attenuated upon treatment with $\mathrm{BaCl}_{2}$ and TEA but not 4-AP and Gli, which manifested in the vasodilatory effects related to $\mathrm{K}^{+}$ channels. The relationship between $\mathrm{Ca}^{2+}$ channels and the vasodilation effects of GPS was further explored in this study. The data showed that GPS dose-dependently attenuated the contraction of high $\mathrm{K}^{+}$depolarized aortic rings induced by gradually increasing $\mathrm{CaCl}_{2}(0.1-10 \mathrm{mM})$ input in $\mathrm{Ca}^{2+}$-free solution; in addition, GPS obviously decreased the $\left[\mathrm{Ca}^{2+}\right]_{\text {in }}$ fluorescence intensity induced by $\mathrm{KCl}$ and $\mathrm{CaCl}_{2}$ in $\mathrm{A} 7 \mathrm{r} 5$ cells, which indicated that GPS inhibited extracellular calcium influx, resulting in vasodilation. PE-induced contractions in $\mathrm{Ca}^{2+}$-free solution are ascribed to intracellular $\mathrm{Ca}^{2+}$ release via activation of $\mathrm{PKC} / \mathrm{Rho}$-kinase- and $\mathrm{IP}_{3} \mathrm{R} / \mathrm{RYR}$ - 


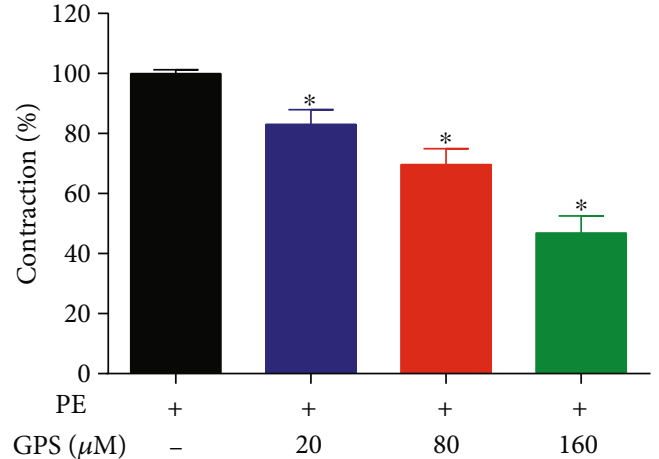

(a)

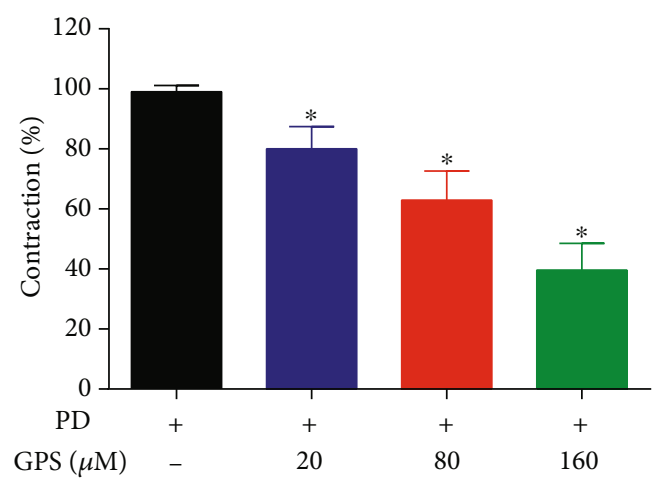

(c)

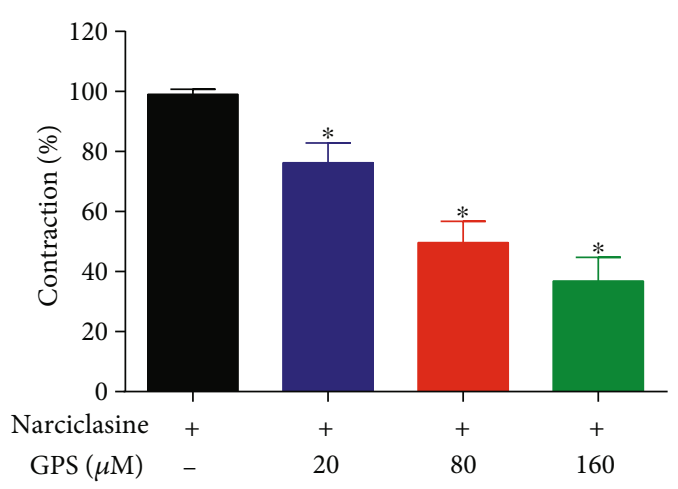

(b)

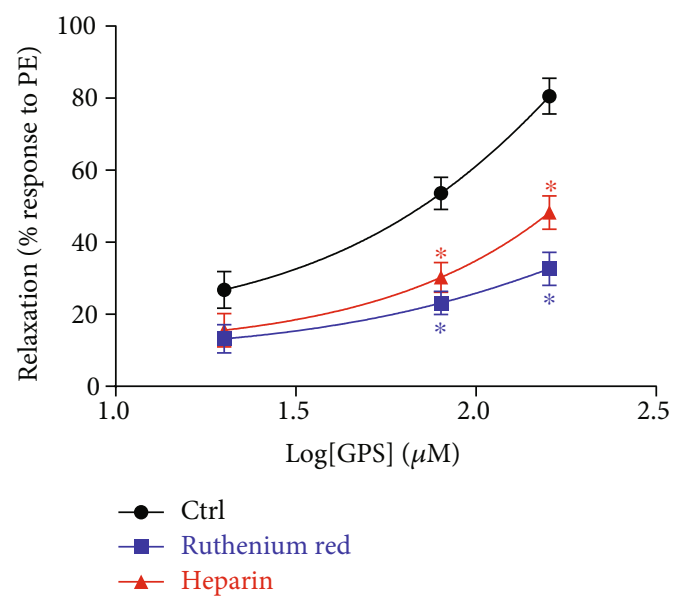

(d)

FIGURE 6: Effects of GPS treatment on intracellular $\mathrm{Ca}^{2+}$ release. (a) Endothelium-denuded aortic rings were precontracted with PE, (b) narciclasine, and (c) phorbol-12,13-diacetate (PD), followed by GPS $(20,80$, and $160 \mu \mathrm{M})$ treatment and detection of the vasorelaxation of the rings in $\mathrm{Ca}^{2+}$-free Krebs solution. (d) Endothelium-denuded aortic rings were incubated with ruthenium red and heparin in $\mathrm{Ca}^{2+}$-free Krebs solution, and then, the rings were treated with GPS $(20,80$, and $160 \mu M)$ after precontracted with PE. Data are presented as mean $\pm \operatorname{SEM}(n=6) .{ }^{*} p<0.05$ compared to the control group.

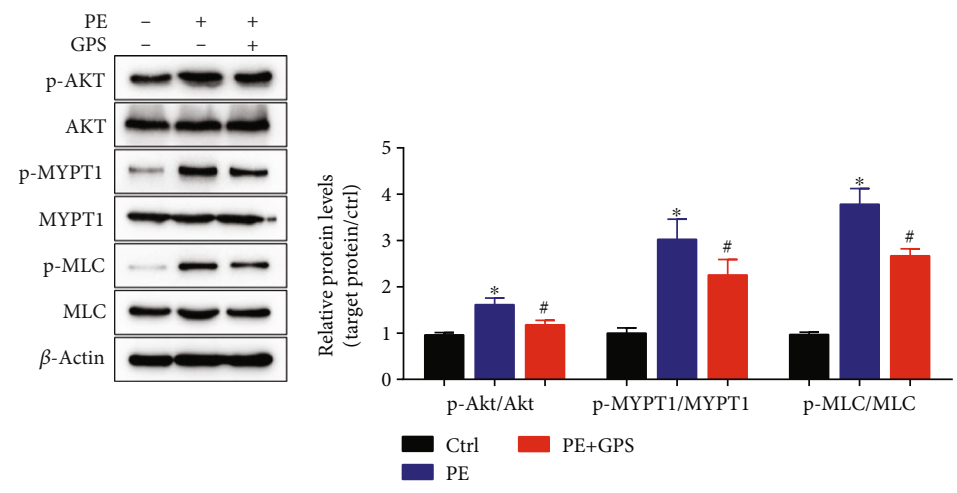

(a)

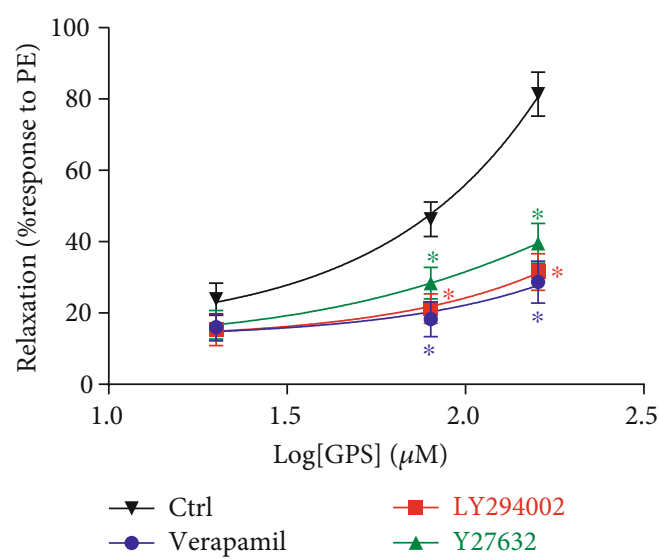

(b)

Figure 7: Effects of GPS on the PI3K/Akt/Rho-kinase pathway. (a) Protein expression levels of p-Akt, Akt, p-MYPT1, MYPT1, p-MLC, and MLC in aortic rings without endothelium were analyzed using western blotting. Data are presented as SEM $(n=3)$. ${ }^{*} p<0.05$ compared to the control group; ${ }^{\#} p<0.05$ compared to the PE group. (b) Endothelium-denuded aortic rings were preincubated with verapamil, LY294002, and Y27632, and then, the rings were treated with GPS $(20,80$, and $160 \mu M)$ after precontracted with PE. Data are presented as mean \pm SEM $(n=6) .{ }^{*} p<0.05$ compared to the control group. 


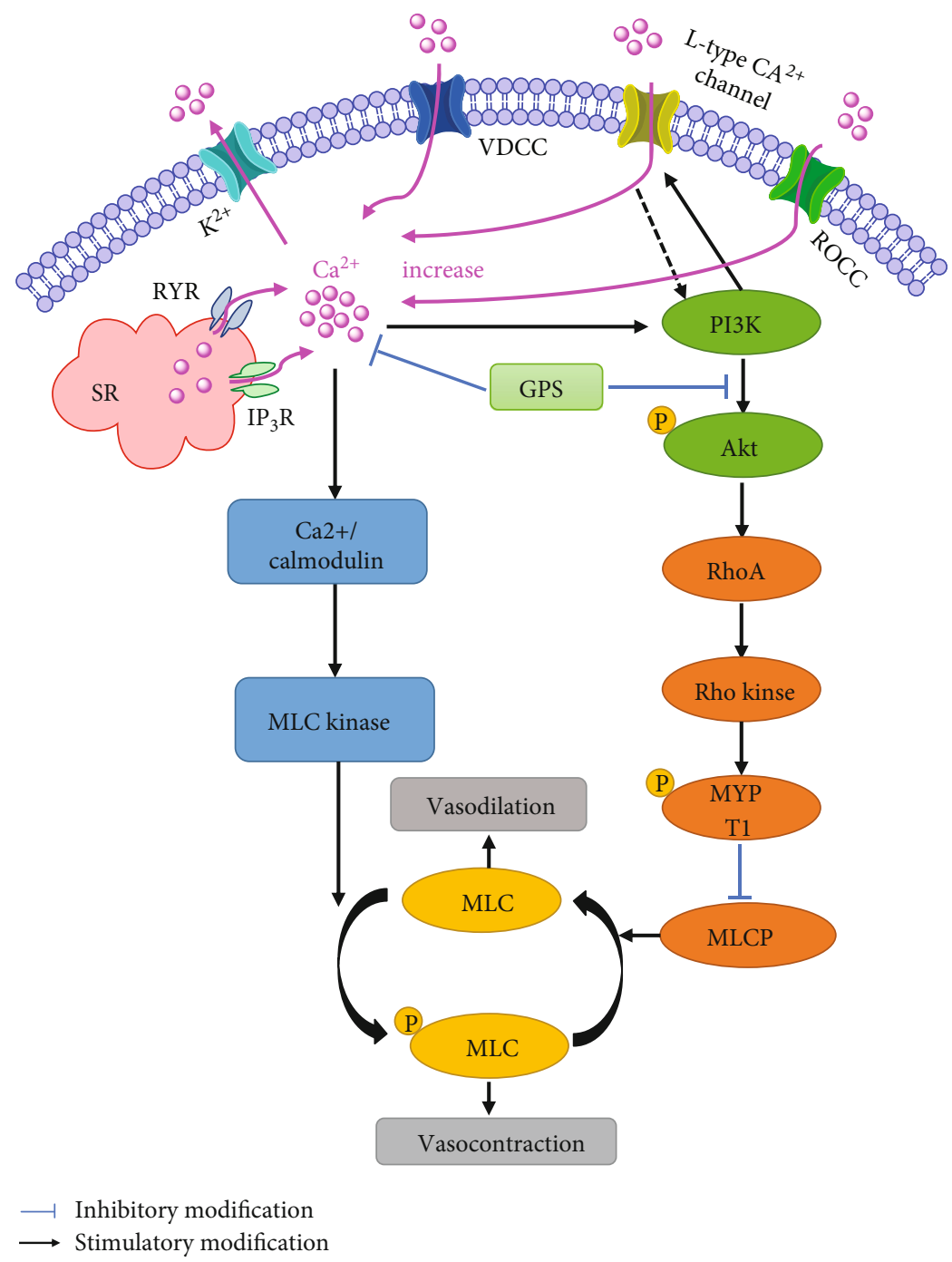

FIGURE 8: Schematic representation of the underlying mechanisms of the GPS-promoted vasodilatation effects in aortic rings. (1) GPS inhibited extracellular $\mathrm{Ca}^{2+}$ influx in the cell membrane and intracellular $\mathrm{Ca}^{2+}$ release through $\mathrm{IP}_{3} \mathrm{R}$ - and $\mathrm{RYR}^{2}$-mediated $\mathrm{Ca}^{2+}$ channels in the sarcoplasmic reticulum by inhibition of VDCC and ROCC. (2) GPS may activate $\mathrm{K}^{+}$channels. (3) GPS inhibited PI3K/Akt/Rho-kinase and L-type $\mathrm{Ca}^{2+}$ channel pathways.

mediated $\mathrm{Ca}^{2+}$ sensitization $[16,31,35]$. Our results indicated that GPS treatment significantly decreased Rhokinase activator- (narciclasine-) and PKC activator- (phorbol-12,13-diacetate-) mediated contraction, and the vasoconstriction of GPS was attenuated upon pretreatment with RYR inhibitor (ruthenium red) and $\mathrm{IP}_{3} \mathrm{R}$ inhibitor (heparin) in aortic rings without $\mathrm{Ca}^{2+}$. These results indicated that GPS inhibited the upregulation of $\left[\mathrm{Ca}^{2+}\right]_{\text {in }}$ via blockade of both extracellular $\mathrm{Ca}^{2+}$ influx in the cell membrane and intracellular $\mathrm{Ca}^{2+}$ release through $\mathrm{IP}_{3} \mathrm{R} / \mathrm{RYR}$-mediated $\mathrm{Ca}^{2+}$ channels in the sarcoplasmic reticulum by inhibition of VDCC and ROCC, and this inhibitory effect may be closely related to Rho-kinase- and PKC-induced phosphorylation of MLC $[11,36]$.

It is well documented that activation of the PI3K/Akt pathway significantly enhances the contraction of VSM through stimulation of the L-type $\mathrm{Ca}^{2+}$ channel and activation of Rho-kinase $[37,38]$. As shown in Figure $8, \mathrm{Ca}^{2+}$ binds to calmodulin in the cytoplasm, activates MLC kinase, phosphorylate MLC, and finally causes vasoconstriction [11, 39]. On the other hand, Rho-kinase can inhibit MLC phosphatase via phosphorylation of MYPT1, resulting in MLC constantly being in the phosphorylated state but not in the dephosphorylated state, which eventually leads to vasoconstriction [4042]. Our results indicated that treatment with GPS significantly decreased the PE-upregulated levels of Akt, MLC, and MYPT1 phosphorylation. L-type $\mathrm{Ca}^{2+}$ channel inhibitor (verapamil), PI3K/Akt inhibitor (LY294002), and Rhokinase inhibitor (Y27632) were used to confirm that the vasodilatory effect of GPS on aortic rings involves regulation of the PI3K/Akt/Rho-kinase signaling pathway, as evidenced by the fact that vasodilatory effects of GPS were significantly attenuated compared to the control group upon pretreatment with these three inhibitors. Therefore, we suggested that GPS inhibited PI3K/Akt/Rho-kinase signaling pathway leading to vasodilation of aortic rings. 


\section{Conclusions}

In summary, the present study demonstrates for the first time that GPS has evident vasodilation effects that are endothelium-independent, and the underlying mechanisms of action for these effects involve the activation of $\mathrm{K}^{+}$channels and inhibition of $\mathrm{Ca}^{2+}$ channels by suppressing the activation of the $\mathrm{PI} 3 \mathrm{~K} / \mathrm{Akt} / \mathrm{Rho}$-kinase signaling pathway.

\section{Data Availability}

The research article data used to support the findings of this study are included within the article.

\section{Conflicts of Interest}

All authors declare that there is no conflict of interest.

\section{Authors' Contributions}

W.C. and R.Z. conceived and designed the experiments; S.X. and F.N coordinated the experiments and manuscript writing; J.Q. and H.H. conducted the experiments and analyzed the data.

\section{Acknowledgments}

This project was supported by the Guangzhou University of Chinese Medicine, the Pearl River Talent Recruitment Program of Guangdong Province [grant number 2017GC010361], and the Department of Education of Guangdong Province [grant number 2016KCXTD015].

\section{References}

[1] C. Wang, Y. Yuan, M. Zheng et al., "Association of age of onset of hypertension with cardiovascular diseases and mortality," Journal of the American College of Cardiology, vol. 75, no. 23, pp. 2921-2930, 2020.

[2] B. Ning, Y. Chen, A. B. Waqar et al., "Hypertension enhances advanced atherosclerosis and induces cardiac death in Watanabe heritable hyperlipidemic rabbits," American Journal of Pathology, vol. 188, no. 12, pp. 2936-2947, 2018.

[3] F. G. Dunn, "Hypertension and myocardial infarction," Journal of the American College of Cardiology, vol. 1, no. 2, pp. 528-532, 1983.

[4] C. Rosendorff, "Endothelin, vascular hypertrophy, and hypertension," Cardiovascular Drugs and Therapy, vol. 10, no. 6, pp. 795-802, 1997.

[5] K. Hu, Q. Zhou, Y. Jiang et al., "Association between Frailty and Mortality, Falls, and Hospitalization among Patients with Hypertension: A Systematic Review and Meta-Analysis," Biomed Research International, vol. 2021, 10 pages, 2021.

[6] P. M. Kearney, M. Whelton, K. Reynolds, P. Muntner, P. K. Whelton, and J. He, "Global burden of hypertension: analysis of worldwide data," Lancet, vol. 365, no. 9455, pp. 217-223, 2005.

[7] D. F. Bohr and R. C. Webb, "Vascular smooth muscle function and its changes in hypertension," American Journal of Medicine, vol. 77, no. 4, pp. 3-16, 1984.
[8] F. Dong, J. Zhang, S. Zhu, T. Lan, J. Yang, and L. Li, "Chrysin alleviates chronic hypoxia-induced pulmonary hypertension by reducing intracellular calcium concentration in pulmonary arterial smooth muscle cells," Journal of Cardiovascular Pharmacology, vol. 74, no. 5, pp. 426-435, 2019.

[9] J. L. Wilson, R. Warburton, L. Taylor, D. Toksoz, N. Hill, and P. Polgar, "Unraveling endothelin-1 induced hypercontractility of human pulmonary artery smooth muscle cells from patients with pulmonary arterial hypertension," PloS One, vol. 13, no. 4, article e0195780, 2018.

[10] Y. Zhu, J. Qu, L. He et al., "Calcium in vascular smooth muscle cell elasticity and adhesion: novel insights into the mechanism of action," Frontiers in Physiology, vol. 10, p. 852, 2019.

[11] Z. Liu and R. A. Khalil, "Evolving mechanisms of vascular smooth muscle contraction highlight key targets in vascular disease," Biochemical Pharmacology, vol. 153, pp. 91-122, 2018.

[12] S. Niazmand, E. Fereidouni, M. Mahmoudabady, and M. Hosseini, " $<\mathrm{i}>$ Teucrium polium $</ \mathrm{i}>$-induced vasorelaxation mediated by endothelium-dependent and endotheliumindependent mechanisms in isolated rat thoracic aorta," Pharmacognosy Research, vol. 9, no. 4, pp. 372-377, 2017.

[13] A. Gutierrez, C. Contreras, A. Sanchez, and D. Prieto, "Role of phosphatidylinositol 3-kinase (PI3K), mitogen-activated protein kinase (MAPK), and protein kinase $\mathrm{C}$ (PKC) in calcium signaling pathways linked to the $\alpha 1$-Adrenoceptor in resistance arteries," Frontiers in Physiology, vol. 10, p. 55, 2019.

[14] Y. Miyamoto, G. G. Feng, S. Satomi, K. Tanaka, Y. Fujiwara, and H. Kinoshita, "Phosphatidylinositol 3-kinase inhibition induces vasodilator effect of sevoflurane via reduction of Rho kinase activity," Life Sciences, vol. 177, pp. 20-26, 2017.

[15] F. Morello, A. Perino, and E. Hirsch, "Phosphoinositide 3kinase signalling in the vascular system," Cardiovascular Research, vol. 82, no. 2, pp. 261-271, 2008.

[16] T. Kitazawa and K. Kitazawa, "Size-dependent heterogeneity of contractile $\mathrm{Ca} 2+$ sensitization in rat arterial smooth muscle," Journal of Physiology, vol. 590, no. 21, pp. 5401-5423, 2012.

[17] M. S. Siobal, "Pulmonary vasodilators," Respiratory Care, vol. 52, no. 7, pp. 885-899, 2007.

[18] J. R. Richards, D. Garber, E. G. Laurin et al., "Treatment of cocaine cardiovascular toxicity: a systematic review," Clinical Toxicology, vol. 54, no. 5, pp. 345-364, 2016.

[19] W. Zhou, J. Ouyang, H. Wang, and X. Wang, "Antidermatophyte activity of the Gentiopicroside-rich n-butanol fraction from Gentiana siphonantha Maxim. Root on a Guinea pig model of dermatophytosis," Complementary Medicine Research, vol. 26, no. 1, pp. 31-38, 2019.

[20] C. Chen, Y. Y. Wang, Y. X. Wang et al., "Gentiopicroside ameliorates bleomycin-induced pulmonary fibrosis in mice via inhibiting inflammatory and fibrotic process," Biochemical and Biophysical Research Communications, vol. 495, no. 4, pp. 2396-2403, 2018.

[21] R. Kesavan, U. R. Potunuru, B. Nastasijević, A. T, G. Joksić, and M. Dixit, "Inhibition of vascular smooth muscle cell proliferation by Gentiana lutea root extracts," PloS One, vol. 8, no. 4, article e61393, 2013.

[22] A. Rojas, M. Bah, J. I. Rojas, and D. M. Gutiérrez, "Smooth muscle relaxing activity of gentiopicroside isolated from Gentiana spathacea," Planta Medica, vol. 66, no. 8, pp. 765-767, 2000. 
[23] A. Ferro, M. Coash, T. Yamamoto, J. Rob, Y. Ji, and L. Queen, "Nitric oxide-dependent beta2-adrenergic dilatation of rat aorta is mediated through activation of both protein kinase A and Akt," British Journal of Pharmacology, vol. 143, no. 3, pp. 397-403, 2004.

[24] Y. Huang, X. Wu, M. Wu et al., "Anti-hypertensive and vasodilatory effects of Qingda granules by suppression of calcium influx and the AKT pathway," Journal of Cardiovascular Pharmacology, vol. 74, no. 6, pp. 549-557, 2019.

[25] S. Godo and H. Shimokawa, "Endothelial functions," Arteriosclerosis, Thrombosis, and Vascular Biology, vol. 37, no. 9, pp. e108-e114, 2017.

[26] K. Yoshioka, N. Sugimoto, N. Takuwa, and Y. Takuwa, "Essential role for class II phosphoinositide 3-kinase alpha-isoform in $\mathrm{Ca} 2+$-induced, Rho- and Rho kinase-dependent regulation of myosin phosphatase and contraction in isolated vascular smooth muscle cells," Molecular Pharmacology, vol. 71, no. 3, pp. 912-920, 2007.

[27] R. S. Owen, J. P. Carpenter, R. A. Baum, L. J. Perloff, and C. Cope, "Magnetic resonance imaging of angiographically occult runoff vessels in peripheral arterial occlusive disease," New England Journal of Medicine, vol. 326, no. 24, pp. 15771581, 1992.

[28] K. Satoh, "Development of novel therapies for cardiovascular diseases by clinical application of basic research," Circulation Journal, vol. 81, no. 11, pp. 1557-1563, 2017.

[29] S. Yang, Z. Xu, C. Lin et al., "Schisantherin A causes endothelium-dependent and -independent vasorelaxation in isolated rat thoracic aorta," Life Sciences, vol. 245, article 117357, 2020.

[30] A. R. Marks, "Calcium channels expressed in vascular smooth muscle," Circulation, vol. 86, 6 Suppl, pp. III61-III67, 1992.

[31] G. Y. Hu, C. Peng, X. F. Xie, L. Xiong, S. Y. Zhang, and X. Y. Cao, "Patchouli alcohol isolated from _Pogostemon cablin_ mediates endothelium- independent vasorelaxation by blockade of $\mathrm{Ca}^{2+}$ channels in rat isolated thoracic aorta," Journal of Ethnopharmacology, vol. 220, pp. 188-196, 2018.

[32] L. Zhao, J. Ye, G. T. Wu, X. J. Peng, P. F. Xia, and Y. Ren, “Gentiopicroside prevents interleukin-1 beta induced inflammation response in rat articular chondrocyte," Journal of Ethnopharmacology, vol. 172, pp. 100-107, 2015.

[33] G. Mahendran, G. Thamotharan, S. Sengottuvelu, and V. N. Bai, "Evaluation of anticonvulsant, sedative, anxiolytic, and phytochemical profile of the methanol extract from the aerial parts of Swertia corymbosa (Griseb.) wight ex C.B. Clarke," BioMed Research International, vol. 2014, Article ID 542385, 9 pages, 2014.

[34] M. F. Dogan, O. Yildiz, S. O. Arslan, and K. G. Ulusoy, "Potassium channels in vascular smooth muscle: a pathophysiological and pharmacological perspective," Fundamental and Clinical Pharmacology, vol. 33, no. 5, pp. 504-523, 2019.

[35] M. Wiciński, B. Malinowski, P. Rajewski et al., "Resveratrol's impact on vascular smooth muscle cells hyporeactivity: the role of Rho-kinase inhibition," BioMed Research International, vol. 2020, Article ID 9012071, 8 pages, 2020.

[36] S. B. Patil and K. N. Bitar, "RhoA- and PKC-alpha-mediated phosphorylation of MYPT and its association with HSP27 in colonic smooth muscle cells," American Journal of Physiology: Gastrointestinal and Liver Physiology, vol. 290, no. 1, pp. G83G95, 2006.
[37] Y. M. Seok, M. A. Azam, Y. Okamoto et al., "Enhanced Ca2+dependent activation of phosphoinositide 3-kinase class II $\alpha$ isoform-Rho axis in blood vessels of spontaneously hypertensive rats," Hypertension, vol. 56, no. 5, pp. 934-941, 2010.

[38] H. Liu, Z. Chen, J. Liu, L. Liu, Y. Gao, and D. Dou, "Endothelium-independent hypoxic contraction of porcine coronary arteries may be mediated by activation of phosphoinositide 3-kinase/Akt pathway," Vascular Pharmacology, vol. 61, no. 2-3, pp. 56-62, 2014.

[39] H. Raina, J. Zacharia, M. Li, and W. G. Wier, "Activation by $\mathrm{Ca} 2+/$ calmodulin of an exogenous myosin light chain kinase in mouse arteries," Journal of Physiology, vol. 587, no. 11, pp. 2599-2612, 2009.

[40] A. Aburima, K. S. Wraith, Z. Raslan, R. Law, S. Magwenzi, and K. M. Naseem, "cAMP signaling regulates platelet myosin light chain (MLC) phosphorylation and shape change through targeting the RhoA-Rho kinase-MLC phosphatase signaling pathway," Blood, vol. 122, no. 20, pp. 3533-3545, 2013.

[41] T. Szasz and R. C. Webb, "Rho-mancing to sensitize calcium signaling for contraction in the vasculature: role of rho kinase," Advances in Pharmacology, vol. 78, pp. 303-322, 2017.

[42] D. P. Wilson, M. Susnjar, E. Kiss, C. Sutherland, and M. P. Walsh, "Thromboxane A2-induced contraction of rat caudal arterial smooth muscle involves activation of $\mathrm{Ca} 2+$ entry and $\mathrm{Ca} 2+$ sensitization: Rho-associated kinase-mediated phosphorylation of MYPT1 at Thr-855, but not Thr-697," Biochemicasl Journal, vol. 389, no. 3, pp. 763-774, 2005. 